\title{
Immediate and Short-Term Outcomes of Percutaneous Transvenous Mitral Commissurotomy on Global and Regional Right Ventricular Strain by Speckle-Tracking Echocardiography
}

\author{
Deepak Maheshwari, Sahil Sareen, Himanshu Mahla, Shashi Mohan Sharma \\ Department of Cardiology, Sawai Man Singh Hospital, Jaipur, Rajasthan, India \\ ORCID: \\ Deepak Maheshwari: https://orcid.org/0000-0003-0493-0005 \\ Sahil Sareen: https://orcid.org/0000-0002-1537-7826 \\ Himanshu Mahla: https://orcid.org/0000-0002-0901-2249 \\ Shashi Mohan Sharma: https://orcid.org/0000-0002-3243-7720
}

\section{Abstract}

Objectives: The study aimed to determine short- and long-term improvement on global and regional right ventricular (RV) strain after successful treatment by percutaneous transvenous mitral commissurotomy (PTMC). Furthermore, we endeavored to define the normal values of RV strain in a healthy age- and sex-matched population that may serve as reference for future investigators. Methods: The interventional case-control study was done on consecutive patients who were admitted in the department of cardiology for balloon mitral valvotomy (BMV) from April 2018 to July 2019. One hundred and forty-eight patients with isolated severe mitral stenosis (MS) in sinus rhythm were assessed for RV function by two-dimensional speckle tracking calculating RV global longitudinal strain (GLS-RV) and longitudinal strain of the free wall (GLS-RVFW) before and after BMV and compared with seventy-two healthy age-matched controls for a 6-month follow-up. Results: At baseline, the GLS of the right ventricle and free wall strain was significantly less among cases as compared to controls (GLS-RV median 20 vs. 23.3, $P<0.0001$ and GLS-RVFW median 23 vs. 27, $P<0.0001)$. Post-PTMC, the global and regional longitudinal RV strain improved significantly at $24 \mathrm{~h}$ and 6 months post procedure and became comparable to that of the control population at 6-month follow-up (cases vs. controls: median GLS-RV [23 vs. 23.3, $P=0.774]$ and GLS-RVFW [27 vs. $27, P=0.558]$ ). Conclusions: PTMC causes significant immediate and long-term improvement in the RV strain and can serve as a good prognostic marker for the outcomes in patients with isolated MS.

Keywords: Free wall right ventricular strain, global right ventricular strain, mitral stenosis

\section{INTRODUCTION}

Mitral stenosis (MS) is a common occurrence associated with rheumatic fever (in developing countries) and degenerative diseases (in developed countries). It is due to decreased mitral valve orifice area (MVOA), consequently leading to elevation in the pulmonary artery-venous pressure. ${ }^{[1]}$

Patients with MS have significant right ventricular (RV) systolic dysfunction, ${ }^{[2]}$ and RV failure plays an important role in the development of clinical symptoms, significantly affecting exercise capacity, prognosis, and survival of patients

Received: 19-01-2021 Revised: 08-03-2021 Accepted: 25-03-2021 Published Online: 05-07-2021

\section{Access this article online}

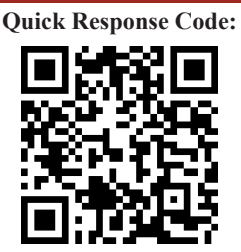

Website:

http://www.ijcva.com

DOI:

10.4103/ijca.ijca_5_21 with pure MS. ${ }^{[3,4]} \mathrm{RV}$ function may also be impaired by the direct involvement of myocardial tissue or through the reactive changes of the pulmonary arteriolar vasculature caused by a passive increase in left atrial pressure and pulmonary hypertension. ${ }^{[5,6]}$

The evaluation of global and regional RV function is difficult because of its asymmetric and complex anatomy. ${ }^{[7,8]}$ Better RV

Address for correspondence: Dr. Sahil Sareen D136 Bapu Nagar, Jaipur - 302 015, Rajasthan, India. E-mail: sahilsareenmd@gmail.com

This is an open access journal, and articles are distributed under the terms of the Creative Commons Attribution-NonCommercial-ShareAlike 4.0 License, which allows others to remix, tweak, and build upon the work non-commercially, as long as appropriate credit is given and the new creations are licensed under the identical terms.

For reprints contact: WKHLRPMedknow_reprints@wolterskluwer.com

How to cite this article: Maheshwari D, Sareen S, Mahla H, Sharma SM. Immediate and short-term outcomes of percutaneous transvenous mitral commissurotomy on global and regional right ventricular strain by speckle-tracking echocardiography. Int J Cardiovasc Acad 2021;7:39-44. 
function analysis has been obtained by magnetic resonance imaging, but the method is costly and available in few institutions. ${ }^{[9]}$ On the other hand, transthoracic echocardiography is a noninvasive and widely used technique that has reproducible and concordant results with other imaging methods. ${ }^{[10]}$ Until now, tissue Doppler imaging and Doppler-derived strain and strain rate analysis are the most widely used techniques for the evaluation of RV myocardial function. ${ }^{[1-14]}$ However, those measurements have major disadvantages such as angle dependence, limited spatial resolution, and deformation analysis in one dimension. ${ }^{[15]}$

Two-dimensional (2D) strain and strain rate imaging has been developed for the quantitative assessment of global and regional myocardial function. This technique is based on gray scale images that are analyzed by the dedicated software system. Although 2D strain imaging has been frequently used to investigate left ventricular (LV) function, little is known about global and segmental RV function. ${ }^{[16,17]}$ Various studies have demonstrated the importance of $2 \mathrm{D}$ strain and strain rate analysis in assessing RV function in different disorders. However, there are only a few studies, which assessed 2D RV strain and strain rate in patients with isolated MS. ${ }^{[18]}$

$\mathrm{RV}$ dysfunction in isolated severe MS patients has prognostic significance. Among the treatment surgeries, percutaneous transvenous mitral commissurotomy (PTMC) has become established as a safe and effective treatment for MS and remains the treatment of choice in patients with a favorable anatomy. ${ }^{[19-21]}$ Global RV function of the pressure-overloaded right ventricle in patients with MS and pulmonary hypertension after successful PTMC has not been well defined. Strain imaging by speckle-tracking echocardiography is a novel and sensitive technique for determining ventricular function. The global longitudinal strain (GLS) of the left ventricle is now well defined in the normal population by various vendors. However, there is a paucity of data regarding the longitudinal RV strain, both global and regional in the normal population of our country.

Thus, the study was conducted with a primary objective to determine short- and long-term improvement on global and regional RV strain after successful treatment by PTMC by speckled echocardiography. The secondary objective of the study was to define the normal values of RV strain in a healthy age- and sex-matched population that may serve as reference for future investigators.

\section{Methods}

The interventional case-control study (type) was done on consecutive patients who were admitted in the department of cardiology for balloon mitral valvotomy (BMV) from April 2018 to July 2019.

The sample size calculation was done based on the study of Kumar et al. ${ }^{[22]}$ who observed the mean values of mid RV free wall systolic of $-1.98 \pm 0.76$ in controls and $-3.21 \pm 2.99$ in cases and apical RV free wall systolic of $-1.04 \pm 0.70$ in controls and $-1.49 \pm 0.96$ in cases. Taking these values as reference and sample size ratio as $2: 1$, the minimum required sample size with $90 \%$ power of study and $5 \%$ level of significance was 66 patients for controls and 132 patients for cases. To reduce margin of error, we have taken almost more than twice the calculated sample size, and the total sample size taken was 218 (148 cases and 70 controls).

The study patients were included as per the inclusion exclusion criteria.

\section{Ethical statement}

The study was approved by the insitutional ethical committee of the hospital. (SMS/R/31907).

\section{Inclusion criteria}

- $\quad$ Patients with age $>18$ years

- Isolated severe rheumatic MS who were admitted for BMV and underwent the same during hospital stay

- Patients in sinus rhythm/AF

- $\quad$ New York Heart Association (NYHA) functional class 2/3 pre procedure.

\section{Exclusion criteria}

Patients with

- Diabetes mellitus, hypertension, and coronary artery disease

- Pericardial disease

- Atrioventricular conduction abnormalities or any bundle branch blocks on the electrocardiogram (ECG)

- Moderate-to-severe valvular disease other than MS

- Chronic obstructive pulmonary disease

- Abnormal serum electrolyte levels

- Impaired LV systolic function (LV ejection fraction $<50 \%$ )

- Pregnancy

- $\quad$ Poor imaging windows or image quality that precluded strain analysis.

After obtaining written informed consent from the patients, details regarding demographic characteristics, symptoms, pulmonary artery hypertension, pulmonary venous hypertension, and NYHA class were recorded. A standard twelve-lead ECG was done for the assessment of cardiac rhythm and features suggesting chamber enlargement and CAD. The left atrial diameter, LV end-systolic and end-diastolic diameters, LV fractional shortening percentage, the thickness of the interventricular septum, and the posterior wall were measured according to the recommendations of the American Society of Echocardiography. ${ }^{[23]}$ The LV ejection fraction was calculated by Simpson's method.

Echocardiography studies were obtained using a Philips iE33 ultrasonographic machine equipped with a $3.5 \mathrm{MHz}$ transducer and interpreted by 2 experienced echocardiographers independently.

Conventional MS indices, such as mean diastolic gradient (MDG), were calculated. MVOA was measured by 
mitral orifice planimetry in parasternal short-axis view and by the Doppler-derived pressure halftime method, and the average area was calculated by the mean value of the two measurements. MS severity was calculated based on hemodynamic data, using MVOA, MDG, and pulmonary artery systolic pressure (PASP), and severe MS is defined as MVOA $<1.5 \mathrm{~cm}^{2}$. PASP was measured by adding $10 \mathrm{mmHg}$, considering the diameter of the inferior vena cava and level of its collapse resulting from respiration, to the value measured by evaluating Bernoulli equation, which is simplified from tricuspid insufficiency velocities. The values of PASP $>35 \mathrm{mmHg}$ were defined as pulmonary hypertension. ${ }^{[24]}$

\section{Strain imaging}

- Echocardiography images were obtained from the apical four-chamber view. Three stable cardiac cycles were stored for each view (five for patients with AF), and Cineloop formats were recorded on the hard disk of the echocardiography device, then used for off-line analysis

- Frame rates used for analysis were 60-80 frames/s. B-mode gray scale images were used by the system and the activity of the stable acoustic markers, named speckles tracked throughout the myocardial tissue

- After manually defining the endocardial border, the software system constitutes an automatic epicardial tracing for each view. When the regions of interest included the whole thickness of the RV, the process is initiated and the software system advanced the tracking frame-by-frame. If the automatically obtained tracking segments are adequate for analysis, the software system accepts to read each region, whereas in-adequate tracking segments are automatically excluded and the investigator manually corrects the contour to achieve optimal tracking

- The myocardium of the RV was divided into two segments (septum and RV free wall [RVFW]), then subdivided into three segments (apical, mid, and basal) that results in a total of six segments. The longitudinal peak systolic strain and peak systolic strain rates were calculated for each segment

- Free wall longitudinal strain was calculated by taking the arithmetic mean of the three values displayed for the RV free wall

- All measurements were obtained by two separate investigators who were unaware of patient characteristics. Measurements were calculated at least three times and the average of these measurements was determined.

\section{Follow-up}

Follow-up was done after 6 months of the intervention where patients' MVOA, MDG, PASP, TAPSE, and RV strain were recorded. The data were entered into MS EXCEL spreadsheet and analysis was done using Statistical Package for the Social Sciences, IBM manufacturer, Chicago, USA, version 21.0.

\section{Statistical analysis}

Categorical variables were presented in number and percentage $(\%)$ and continuous variables were presented as mean \pm standard deviation and median. Normality of data was tested by Kolmogorov-Smirnov test. If the normality was rejected, nonparametric test was used.

Statistical tests were applied as follows:

1. Quantitative variables were compared using MannWhitney test (as the data sets were not normally distributed) between the two groups and Wilcoxon signed-rank test between pre and post

2. Qualitative variables were correlated using Chi-square test.

$P<0.05$ was considered statistically significant.

\section{RESULTS}

The mean age of the cases was 29.82 years and of the controls was 30.2 years with an almost 1:1 M: F gender distribution in both groups $(P>0.05)$ [Table 1]. Majority of the cases belonged to NYHA Class $2(47.97 \%)$ and Class $3(49.32 \%)$ with $2(1.35 \%)$ cases each of NYHA Class 1 and 4.

At baseline, the GLS of the right ventricle and free wall strain was significantly less among cases as compared to controls (GLS-RV median 20 vs. 23.3, $P<0.0001$ and GLS-RVFW median 23 vs. 27, $P<0.0001$ ) as shown in Table 2.

After the treatment, a significant improvement was noted in MVOA, MDG, PASP, TAPSE, GLS-RV, and GLS-RVFW

\begin{tabular}{lccc}
\hline $\begin{array}{l}\text { Table 1: Comparison of demographic characteristics } \\
\text { between case and control }\end{array}$ & & \\
\hline $\begin{array}{l}\text { Demographic } \\
\text { characteristics }\end{array}$ & Case $(\boldsymbol{n}=148)$ & Control $(\boldsymbol{n}=\mathbf{7 0})$ & $\boldsymbol{P}$ \\
\hline Age (years) & & & \\
Mean \pm SD & $29.82 \pm 7.22$ & $30.2 \pm 6.52$ & 0.499 \\
Median (IQR) & $29(24.500-33)$ & $29.5(25-34)$ & \\
Range & $18-65$ & $19-49$ & \\
Gender, $n(\%)$ & & & \\
Female & $76(51.35)$ & $30(42.86)$ & 0.241 \\
Male & $72(48.65)$ & $40(57.14)$ & \\
\hline
\end{tabular}

SD: Standard deviation, IQR: Interquartile range

Table 2: Comparison of baseline characteristics between case and control

\begin{tabular}{lccc}
\hline $\begin{array}{l}\text { Baseline } \\
\text { characteristics }\end{array}$ & Case $(\boldsymbol{n = 1 4 8 )}$ & Control $(\boldsymbol{n = 7 0 )}$ & $\boldsymbol{P}$ \\
\hline GLS-RV & $19.41 \pm 1.84$ & $23.35 \pm 0.8$ & $<0.0001$ \\
Mean \pm SD & $20(18-20.700)$ & $23.3(22.900-24)$ & \\
Median (IQR) & $14.8-24$ & $21-25$ & \\
Range & & & \\
GLS-RVFW & $22.57 \pm 1.98$ & $26.97 \pm 0.69$ & $<0.0001$ \\
Mean \pm SD & $23(21-24)$ & $27(26.600-27.300)$ & \\
Median (IQR) & $18-27$ & $24.7-28.6$ & \\
Range &
\end{tabular}

GLS-RV: Right ventricular global longitudinal strain, GLS-RVFW:

Right ventricular free wall longitudinal strain, SD: Standard deviation, IQR: Interquartile range 
at $24 \mathrm{~h}$ and 6 months as compared to the baseline $(P<0.0001)$ as shown in Table 3.

Due to the significant improvement after the intervention, as compared to controls, the cases had comparable median GLS-RV (23 vs. 23.3, $P=0.774$ ) and GLS-RVFW (27 vs. $27, P=0.558)$ at 6 months of follow-up [Table 4].

\section{Discussion}

The measurement of RV function does not have a single validated echocardiographic indicator. Literature suggests assessment of various parameters, but the index study selected the improvement in the RV strain as a marker for RV systolic dysfunction since (1) it is a global parameter, (2) encompasses the myocardial contractility of the free wall, (3) has better prognostic power, and (4) correlates with other parameters such as TAPSE, PASP, RV ejection fraction, RV Tei index, and tricuspid $S^{\prime}$ velocity. ${ }^{[25]}$

In this study, comparing nearly 150 patients of rheumatic MS with about half the number of age- and sex-matched controls, we found that the mean global and regional RV strain was significantly lower at baseline in the patient cohort. This was more evident in patients who had longstanding mitral valve stenosis like the ones who had undergone PTMC earlier. The decreased myocardial contractility as seen in the index study with strain imaging has also been seen in previous studies who assessed an association of RV strain and CV outcomes. ${ }^{\text {[26-32] }}$

After undergoing successful PTMC, the global and free wall strain tended to improve even after just $24 \mathrm{~h}$ of the procedure,

\begin{tabular}{|c|c|c|c|}
\hline Variables & Baseline & $24 \mathrm{~h}$ & 6 months \\
\hline MVOA & $1(0.800-1.200)$ & $1.8(1.600-2)^{*}$ & $1.8(1.600-2)^{*}$ \\
\hline MDG & $11(10-15)$ & $6(5-7)^{*}$ & $6(5-7)^{*}$ \\
\hline PASP & $50(40-59)$ & $31(27-40)^{*}$ & $31(27-40)^{*}$ \\
\hline TAPSE & $17(16-19)$ & $18(17-20)^{*}$ & $18(17-20)^{*}$ \\
\hline GLS-RV & $20(18-20.700)$ & $21(20-22)^{*}$ & $23(22.500-24) *$ \\
\hline GLS-RVFW & $23(21-24)$ & $24(23-25)^{*}$ & $27(26-27.700)^{*}$ \\
\hline
\end{tabular}

reiterating a possibility that this immediate improvement in global RV function is due to improved hemodynamics, better LV filling, and RV emptying after BMV. Our findings were in line with other studies..$^{[3,33-35]}$

The greater immediate improvement of global RV strain than RV free wall strain may be because of enhanced LV filling and LV contractility post BMV. However, the strain was still significantly lower at $24 \mathrm{~h}$ post PTMC as compared to the control population values.

On long-term follow-up done at 6 months, despite 4 patients being lost to follow-up, both global and free wall RV strain tended to reach values comparable to the control population. This shows that BMV causes significant improvement in the RV systolic function over time, which may be due to the increased contractility of the longitudinal fibers of RV, which constitutes around $80 \%$ of the RV contraction.

We also observed that there was significant improvement in the MVOA, MDG, PASP, and TAPSE at $24 \mathrm{~h}$ and 6 months of follow-up after the intervention. This further corroborates with the fact that these parameters correlate with the improvement in the RV strain as done by strain echocardiography. Among previous studies also, RVGLS was found to be significantly correlated with RV ejection fraction $(r=-0.50--0.80),{ }^{[31,36-38]}$ TAPSE $(\mathrm{r}=-0.547--0.83)$, RVFAC $(\mathrm{r}=-0.213--0.73)$, tricuspid S' velocity $(r=0.718)$, RV Tei index $(r=0.590),{ }^{[27,31,32,36,39]}$ and PASP $(r=0.56$, $P<0.001){ }^{[40]}$

In this study, we have also tried to determine the normal range and the usefulness of RV global and free wall systolic strain to detect subtle RV systolic abnormalities that has not been done in any Indian study to the best of our knowledge. Literature shows that there are vendor differences and gender and age differences in strain values among different population, ${ }^{[41-44]}$ and thus, each region/ethnicity should consider their own reference values for estimating the RVGLS total and RVGLS-FW strain.

This study has some limitations. First, the cases and controls were known to the operators, so a bias may be present. Second, exclusion of CAD was not done by CT/conventional angiography and LV dysfunction was not ruled out using $\mathrm{GL} / \mathrm{radial} /$ circumferential strain but by the ejection fraction calculated by various standardized methods. Third, a longer follow-up may be required to assess the impact of pre PTMC strain or its lack of improvement on the survival of these

Table 4: Comparison of follow up variables between case and control

\begin{tabular}{lccc}
\hline Follow up variables & Case $(\boldsymbol{n = 1 4 8 )}$ & Control $(\boldsymbol{n = 7 0 )}$ & $\boldsymbol{P}$ \\
\hline GLS-RV (24 h post-PTMC) & $21(20-22)$ & $23.3(22.900-24)$ & $<0.0001$ \\
GLS-RVFW (24 h post-PTMC) & $24(23-25)$ & $27(26.600-27.300)$ & $<0.0001$ \\
GLS-RV (6 months post-PTMC) & $23(22.500-24)$ & $23.3(22.900-24)$ & 0.774 \\
GLS-RVFW (6 months post-PTMC) & $27(26-27.700)$ & $27(26.600-27.300)$ & 0.558 \\
\hline
\end{tabular}

Median values (IQR). GLS-RV: Right ventricular global longitudinal strain, GLS-RVFW: Right ventricular free wall longitudinal strain, IQR: Interquartile range, PTMC: Percutaneous transvenous mitral commissurotomy 
patients. Fourth, in keeping with the current guidelines, ${ }^{[45]}$ only apical view was used to calculate the RV strain, so some areas of RV may be underrepresented.

\section{Conclusions}

$\mathrm{RV}$ systolic function is impaired in patients with severe MS and can be accurately assessed by global and segmental RV strain. Impaired global and segmental RV strain values in these patients are primarily due to increased after load which improve after BMV with reduction in RV afterload. In addition, the study may help foster clinical studies using the normal values of RV GLS in comparing the abnormal GLS of the right ventricle in pulmonary hypertension, congenital heart diseases, and heart failure with reduced ejection fraction in Indian population.

\section{Declaration of patient consent}

The authors certify that they have obtained all appropriate patient consent forms. In the form, the patient (s) has/have given his/her/their consent for his/her/their images and other clinical information to be reported in the journal. The patients understand that their names and initials will not be published and due efforts will be made to conceal their identity, but anonymity cannot be guaranteed.

\section{Financial support and sponsorship}

Nil.

\section{Conflicts of interest}

There are no conflicts of interest.

\section{ReFEREnCES}

1. Pasca I, Dang P, Tyagi G, Pai RG. Survival in Patients with Degenerative Mitral Stenosis: Results from a Large Retrospective Cohort Study. J Am Soc Echocardiogr 2016;29:461-9.

2. Sagie A, Freitas N, Padial LR, Leavitt M, Morris E, Weyman AE, et al. Doppler echocardiographic assessment of long-term progression of mitral stenosis in 103 patients: Valve area and right heart disease. J Am Coll Cardiol 1996;28:472-9.

3. Mohan JC, Sengupta PP, Arora R. Immediate and delayed effects of successful percutaneous transvenous mitral commissurotomy on global right ventricular function in patients with isolated mitral stenosis. Int $\mathrm{J}$ Cardiol 1999;68:217-23.

4. Hirata N, Sakakibara T, Shimazaki Y, Watanabe S, Nomura F, Akamatsu $\mathrm{H}$, et al. Preoperative and postoperative right ventricular function during exercise in patients with mitral stenosis. J Thorac Cardiovasc Surg 1992;104:1029-34.

5. Borer JS, Hochreiter C, Rosen S. Right ventricular function in severe non-ischemic mitral insufficiency. Eur Heart J 1991;12:22-5.

6. Iskandrian AS, Hakki AH, Ren JF, Kotler MN, Mintz GS, Ross J, et al. Correlation among right ventricular preload, afterload and ejection fraction in mitral valve disease: Radionuclide, echocardiographic and hemodynamic evaluation. J Am Coll Cardiol 1984;3:1403-11.

7. Tulevski II, Romkes H, Dodge-Khatami A, van der Wall EE, Groenink M, van Veldhuisen DJ, et al. Quantitative assessment of the pressure and volume overloaded right ventricle: Imaging is a real challenge. Int J Cardiovasc Imaging 2002;18:41-51.

8. Danchin N, Juilliere Y, Schrijen F, Cherrier F. Differential effects on right ventricular function of transient right, left anterior descending and left circumflex coronary occlusions during percutaneous transluminal coronary angioplasty. J Am Coll Cardiol 1991;18:437-42.

9. Sechtem U, Pflugfelder PW, Gould RG, Cassidy MM, Higgins CB. Measurement of right and left ventricular volumes in healthy individuals with cine MR imaging. Radiology 1987;163:697-702.

10. Kaul S, Tei C, Hopkins JM, Shah PM. Assessment of right ventricular function using two-dimensional echocardiography. Am Heart $\mathrm{J}$ 1984;107:526-31.

11. Meluzín J, Spinarová L, Bakala J, Toman J, Krejcí J, Hude P, et al. Pulsed Doppler tissue imaging of the velocity of tricuspid annular systolic motion; A new, rapid, and non-invasive method of evaluating right ventricular systolic function. Eur Heart J 2001;22:340-8.

12. Vitarelli A, Conde Y, Cimino E, Stellato S, D'Orazio S, D'Angeli I, et al. Assessment of right ventricular function by strain rate imaging in chronic obstructive pulmonary disease. Eur Respir J 2006;27:268-75.

13. Kukulski T, Hübbert L, Arnold M, Wranne B, Hatle L, Sutherland GR. Normal regional right ventricular function and its change with age: A Doppler myocardial imaging study. J Am Soc Echocardiogr 2000;13:194-204.

14. Sevimli S, Gundogdu F, Aksakal E, Arslan S, Tas H, Islamoglu Y, et al. Right ventricular strain and strain rate properties in patients with right ventricular myocardial infarction. Echocardiography 2007;24:732-8.

15. Marwick TH. Measurement of strain and strain rate by echocardiography: Ready for prime time? J Am Coll Cardiol 2006;47:1313-27.

16. Leitman M, Lysyansky P, Sidenko S, Shir V, Peleg E, Binenbaum M, et al. Two- dimensional strain - A novel software for real-time quanti- tative echocardiographic assessment of myocardial function. J Am Soc Echocardiogr 2004;17:1021-9.

17. Teske AJ, De Boeck BW, Melman PG, Sieswerda GT, Doevendans PA, Cramer MJ, et al. Echocardio- graphic quantification of myocardial function using tissue deformation imaging, a guide to image acquisition and analysis using tissue Doppler and speckle tracking. Cardiovasc Ultrasound 2007;5:27.

18. Ozdemir AO, Kaya CT, Ozdol C, Candemir B, Turhan S, Dincer I, et al. Two-dimensional longitudinal strain and strain rate imaging for assessing the right ventricular function in patients with mitral stenosis. Echocardiography 2010;27:525-33.

19. Iung B, Garbarz E, Michaud P, Helou S, Farah B, Berdah P, et al. Late results of percutaneous mitral commissurotomy in a series of 1024 patients. Analysis of late clinical deterioration: Frequency, anatomic findings, and predictive factors. Circulation 1999;99:3272-8.

20. Vahanian A, Baumgartner H, Bax J, Butchart E, Dion R, Fillipaatos G, et al. Guidelines on the management of valvular heart disease: The Task Force on the Management of Valvular Heart Disease of the European Society of Cardiology. Eur Heart J 2007;28:230-68.

21. Nishimura RA, Carabello BA, Faxon DP, Freed MD, Lytle BW, et al. ACC/AHA 2008 guideline update on valvular heart disease: Focused update on infective endocarditis: A report of the American College of Cardiology/American Heart Association Task Force on Practice Guidelines: Endorsed by the Society of Cardiovascular Anesthesiologists, Society for Cardiovascular Angiography and Interventions, and Society of Thoracic Surgeons. Circulation 2008;118:887-96.

22. Kumar V, Jose VJ, Pati PK, Jose J. Assessment of right ventricular strain and strain rate in patients with severe mitral stenosis before and after balloon mitral valvuloplasty. Indian Heart J 2014;66:176-82.

23. Gottdiener JS, Bednarz J, Devereux R, Gardin J, Klein A, Manning WJ, et al. American Society of Echocardiography recommendations for use of echocardiography in clinical trials. J Am Soc Echocardiogr 2004; 17:1086-119.

24. Lang RM, Bierig M, Devereux RB, Flachskampf FA, Foster E, Pellikka PA, et al. Recommendations for chamber quantification: A report from the American Society of Echocardiography's guidelines and standards committee and the chamber quantification writing group developed in conjunction with the European Association of Echocardiography, a branch of the European Society of Cardiology. J Am Soc Echocardiogr 2005;18:1440-63.

25. Lang RM, Bierig M, Devereux RB, Flachskampf FA, Foster E, Pellikka PA, et al. Recommendations for chamber quantification: A report from the American Society of Echocardiography's Guidelines and Standards Committee and the Chamber Quantification Writing Group, developed in conjunction with the European Association of Echocardiography, a branch of the European Society of Cardiology. J Am Soc Echocardiogr 2005;18:1440-63.

26. Motoji Y, Tanaka H, Fukuda Y, Ryo K, Emoto N, Kawai H, et al. 
Efficacy of right ventricular free-wall longitudinal speckle-tracking strain for predicting long-term outcome in patients with pulmonary hypertension. Circ J 2013;77:756-63.

27. Choi SW, Park JH, Sun BJ, Park Y, Kim YJ, Lee IS, et al. Impaired two-dimensional global longitudinal strain of left ventricle predicts adverse long-term clinical outcomes in patients with acute myocardial infarction. Int J Cardiol 2015;196:165-7.

28. Fine NM, Chen L, Bastiansen PM, Frantz RP, Pellikka PA, Oh JK, et al. Outcome prediction by quantitative right ventricular function assessment in 575 subjects evaluated for pulmonary hypertension. Circ Cardiovase Imaging 2013;6:711-21.

29. D'Andrea A, Limongelli G, Baldini L, Verrengia M, Carbone A, Di Palma E, et al. Exercise speckle-tracking strain imaging demonstrates impaired right ventricular contractile reserve in hypertrophic cardiomyopathy. Int J Cardiol 2017;227:209-16.

30. Grant AD, Smedira NG, Starling RC, Marwick TH. Independent and incremental role of quantitative right ventricular evaluation for the prediction of right ventricular failure after left ventricular assist device implantation. J Am Coll Cardiol 2012;60:521-8.

31. Park JH, Negishi K, Kwon DH, Popovic ZB, Grimm RA, Marwick TH. Validation of global longitudinal strain and strain rate as reliable markers of right ventricular dysfunction: Comparison with cardiac magnetic resonance and outcome. J Cardiovasc Ultrasound 2014;22:113-20.

32. Park SJ, Park JH, Lee HS, Kim MS, Park YK, Park Y, et al. Impaired $\mathrm{RV}$ global longitudinal strain is associated with poor long-term clinical outcomes in patients with acute inferior STEMI. JACC Cardiovasc Imaging 2015;8:161-9.

33. Drighil A, Bennis A, Mathewson JW, Lancelotti P, Rocha P. Immediate impact of successful percutaneous mitral valve commissurotomy on right ventricular function. Eur J Echocardiogr 2008;9:536-41.

34. Santosh D, Velam V. The immediate and short term impact of successful percutaneous transvenous mitral commissurotomy on right ventricular function. J Cardiovasc Dis Diagn 2015;3:1-7.

35. İnci S, Erol MK, Bakırcı EM, Hamur H, Değirmenci H, Duman H, et al. Effect of percutaneous mitral balloon valvuloplasty on right ventricular functions in mitral stenosis: Short- and mid-term results. Anatol J Cardiol 2015;15:289-96.

36. Vizzardi E, Bonadei I, Sciatti E, Pezzali N, Farina D, D'Aloia A, et al. Quantitative analysis of right ventricular (RV) function with echocardiography in chronic heart failure with no or mild RV dysfunction: Comparison with cardiac magnetic resonance imaging.
J Ultrasound Med 2015;34:247-55.

37. Focardi M, Cameli M, Carbone SF, Massoni A, De Vito R, Lisi M, et al. Traditional and innovative echocardiographic parameters for the analysis of right ventricular performance in comparison with cardiac magnetic resonance. Eur Heart J Cardiovasc Imaging 2015;16:47-52.

38. Lemarié J, Huttin $\mathrm{O}$, Girerd $\mathrm{N}$, Mandry $\mathrm{D}$, Juillière $\mathrm{Y}$, Moulin $\mathrm{F}$, et al. Usefulness of speckle-tracking imaging for right ventricular assessment after acute myocardial infarction: A magnetic resonance imaging/ echocardiographic comparison within the relation between aldosterone and cardiac remodeling after myocardial infarction study. J Am Soc Echocardiogr 2015;28:818-27.e4.

39. Meris A, Faletra F, Conca C, Klersy C, Regoli F, Klimusina J, et al. Timing and magnitude of regional right ventricular function: A speckle tracking-derived strain study of normal subjects and patients with right ventricular dysfunction. J Am Soc Echocardiogr 2010;23:823-31

40. Puwanant S, Park M, Popović ZB, Tang WH, Farha S, George D, et al. Ventricular geometry, strain, and rotational mechanics in pulmonary hypertension. Circulation 2010;121:259-66.

41. Fine NM, Shah AA, Han IY, Yu Y, Hsiao JF, Koshino Y, et al. Left and right ventricular strain and strain rate measurement in normal adults using velocity vector imaging: An assessment of reference values and intersystem agreement. Int J Cardiovasc Imaging 2013;29:571-80.

42. Muraru D, Onciul S, Peluso D, Soriani N, Cucchini U, Aruta P, et al. Sex- and Method-Specific Reference Values for Right Ventricular Strain by 2-Dimensional Speckle-Tracking Echocardiography. Circ Cardiovasc Imaging 2016;9:e003866.

43. Park JH, Choi JO, Park SW, Cho GY, Oh JK, Lee JH, et al. Normal references of right ventricular strain values by two-dimensional strain echocardiography according to the age and gender. Int $\mathrm{J}$ Cardiovasc Imaging 2018;34:177-83.

44. Fine NM, Chen L, Bastiansen PM, Frantz RP, Pellikka PA, Oh JK, et al. Reference Values for Right Ventricular Strain in Patients without Cardiopulmonary Disease: A Prospective Evaluation and Meta-Analysis. Echocardiography 2015;32:787-96.

45. Badano LP, Kolias TJ, Muraru D, Abraham TP, Aurigemma G, Edvardsen T, et al. Standardization of left atrial, right ventricular, and right atrial deformation imaging using two-dimensional speckle tracking echocardiography: A consensus document of the EACVI/ASE/Industry Task Force to standardize deformation imaging. Eur Heart J Cardiovasc Imaging 2018;19:591-600. 